$$
\begin{aligned}
& \text { co } \\
& \text { ston } \\
& \text { scroos }
\end{aligned}
$$




\section{SCHOOLLUNCHES IN EUROPA: EEN VERKENNING VAN DE PRAKTIJK RONDOM SCHOOLLUNGHES IN HET PRIMAIR ONDERWIJS IN EUROPA}

Geertje van Bergen, Monique Vingerhoeds, Coosje Dijkstra \& Ellen van Kleef December 2020

TKI-AF 16098 De Gezonde Schoollunch.

Meer informatie: www.etenopschool.org en etenopschool@wur.nt. 


\section{$\operatorname{ein}_{\operatorname{sen}}^{\operatorname{sen}}$}

Colofon

Dit rapport is gratis te downloaden op https://doi.org/10.18174/536746 en op www.wur.ni/wfbr (onder publicaties).

Dit onderzoek is uitgevoerd door Wageningen Food \& Biobased Research (WFBR), onderdeel van Wageningen University \& Research, Wageningen University (WUR) en Vrije Universiteit Amsterdam (VUU).

Alle rechten voorbehouden. Niets uit deze uitgave mag worden verveelvoudigd, opgeslagen in een geautomatiseerd gegevensbestand of openbaar gemaakt in enige vorm of op enige wijze, hetzij elektronisch, hetzij mechanisch, doôr fotokopieën, opnamen of enige andere manier, zonder voorafgaande schriftelijke toestemming van de uitgever. De uitgever aanvaardt geen aansprakelijkheid voor eventuele fouten of onvolkomenheden: 


\section{Schoollunches een gewoonte in Europa?}

- School biedt een kansrijke setting om bij te dragen aan de ontwikkeling van gezonde eetgewoontes van kinderen

- In Nederland brengen de meeste kinderen hun eigen lunch mee naar de basisschool. Een door school aangeboden lunch is een uitzondering

- Inzichten uit andere Europese landen die een schoollunch aanbieden kunnen in Nederland gebruikt worden voor de ontwikkeling en implementatie van een mogelijke schoollunch. 


\section{Aanpak van deze verkenning}

- Online desk research: informatie gezocht via zoekmachines

- Bronnen die als betrouwbaar werden geclassificeerd:

- Wetenschappelijke artikelen, presentaties en abstracts van conferenties vanaf 2010

- Nationale en Europese onderzoeksrapporten en beleidsdocumenten

- Teksten in talen niet beheerst door de onderzoeker zijn automatisch vertaald via Google Translate 


\section{0 \\ Gov \\ Scroot}

SCHOOLLUNCHES IN EUROPA: DEELNAME EN FINANGIERING 


\section{In veel Europese landen wordt een schoollunch aangeboden}

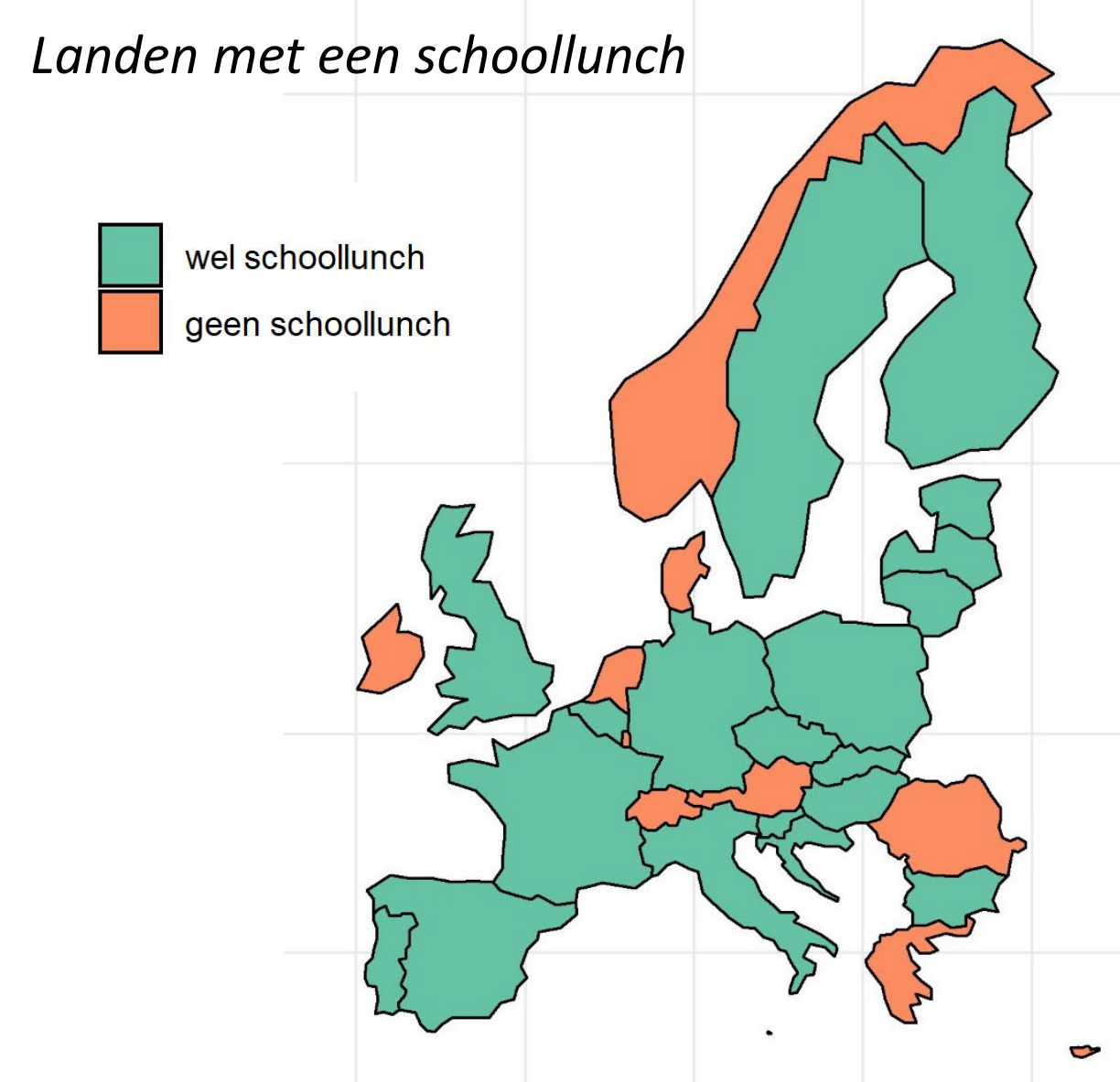




\section{Niet alle kinderen nemen deel aan de schoollunch}
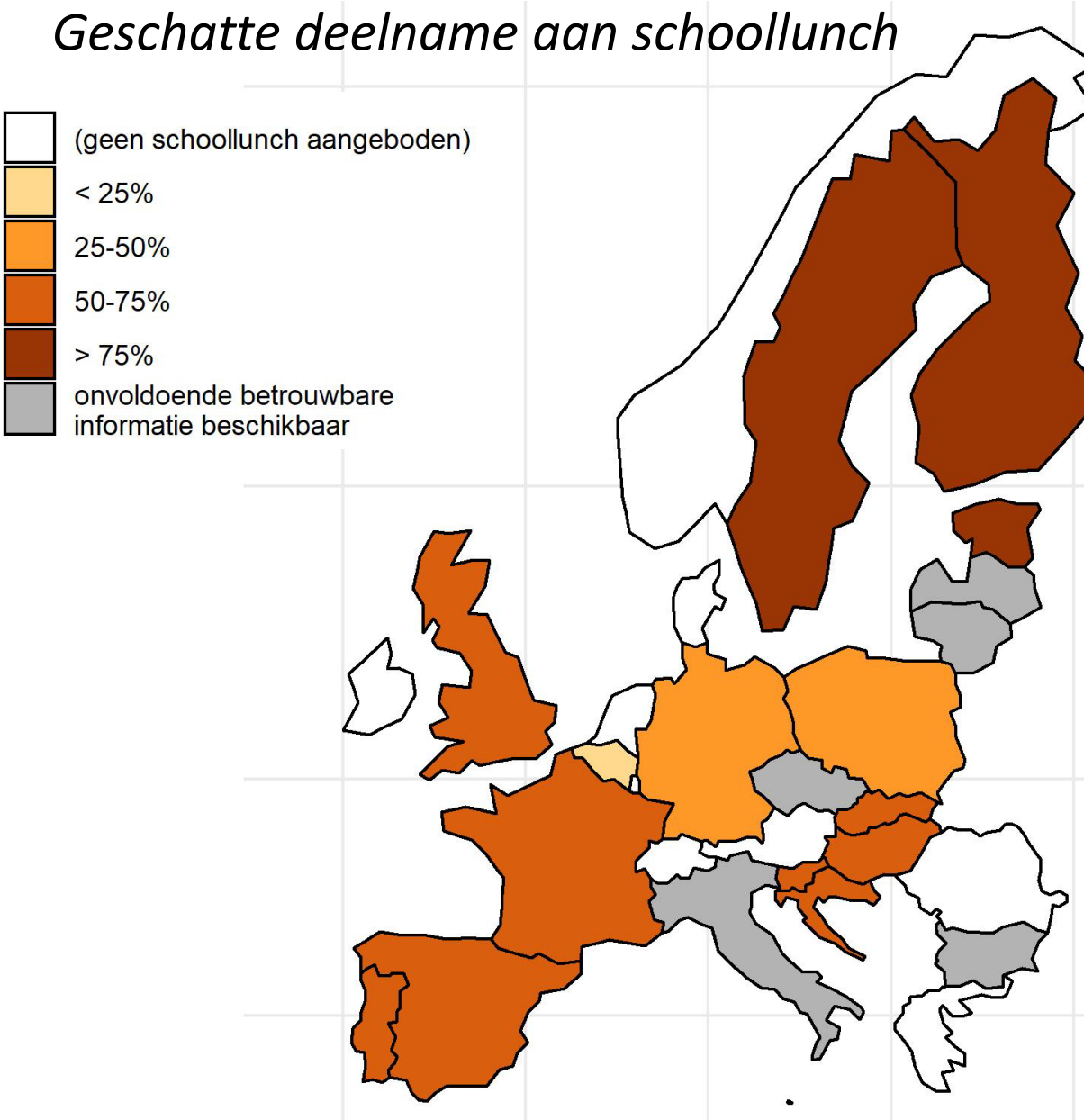

- Deelnemen aan de schoollunch is nergens verplicht

- In verschillende landen wordt wel verwacht dat als kinderen op school blijven tijdens de lunchpauze, ze ook deelnemen aan de schoollunch.

- In Zweden, Finland en Estland is de lunch onderdeel van het schoolcurriculum

- Redenen om niet deel te nemen aan de lunch:

- Halve schooldagen

- Thuis lunchen 


\section{De schoollunch is in bijna alle landen op zijn minst gedeeltelijk gesubsidieerd}

\section{Algemene subsidie}

volledig voor alle kinderen

volledig voor jongere kinderen gedeeltelijk

nee

n.v.t. (geen schoollunch aangeboden) onvoldoende betrouwbare informatie beschikbaar

\section{Extra subsidie (inkomensafhankelijk)}
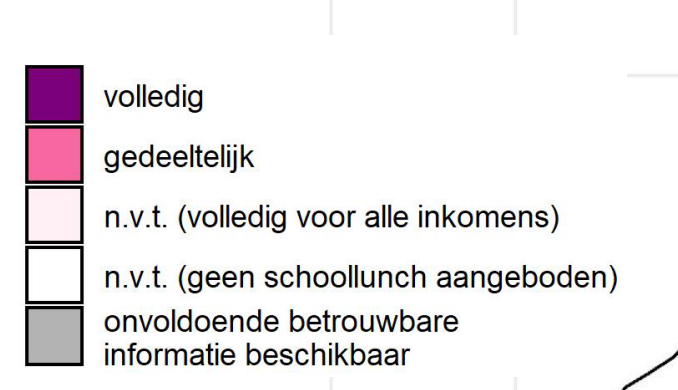

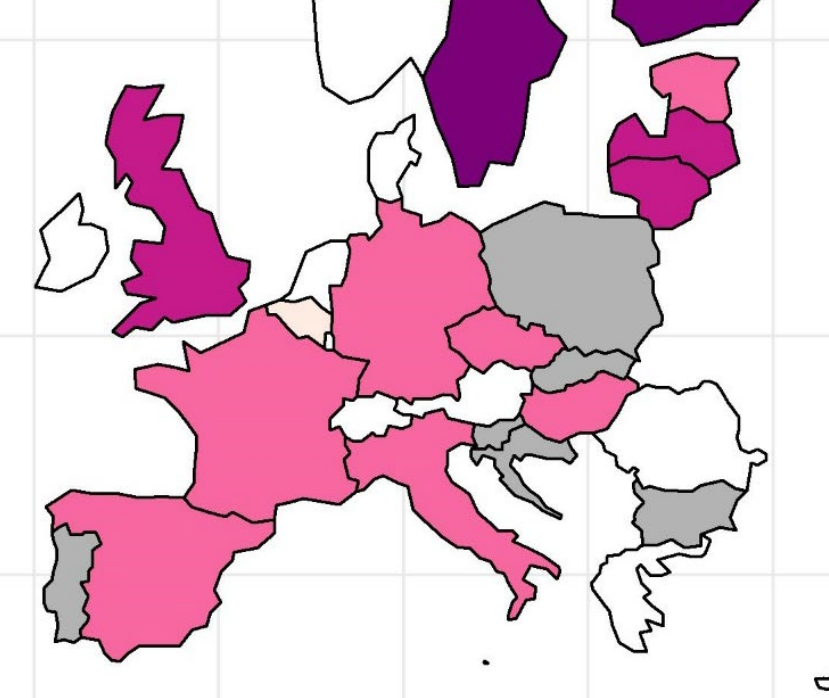




\section{Relatie tussen mate van financiering en deelname aan de schoollunch}

- Deelname aan schoollunches is:

- hoger als de lunch gratis is voor lagere inkomens

- het hoogst als de lunch gratis is voor alle kinderen

- Het aanbieden van een gesubsidieerde schoollunch is geen garantie voor deelname aan de lunch

- Subsidie van de schoollunch aan gezinnen met lage inkomens brengt het risico met zich mee op stigmatisering van armoede 


\section{co
Stot
Sclool}

SCHOOLLUNCHES IN EUROPA: VOEDINGSWAARDE 


\section{Nationale richtlijnen voor de kwaliteit van schoollunches}

Productrichtlijnen voor schoollunches
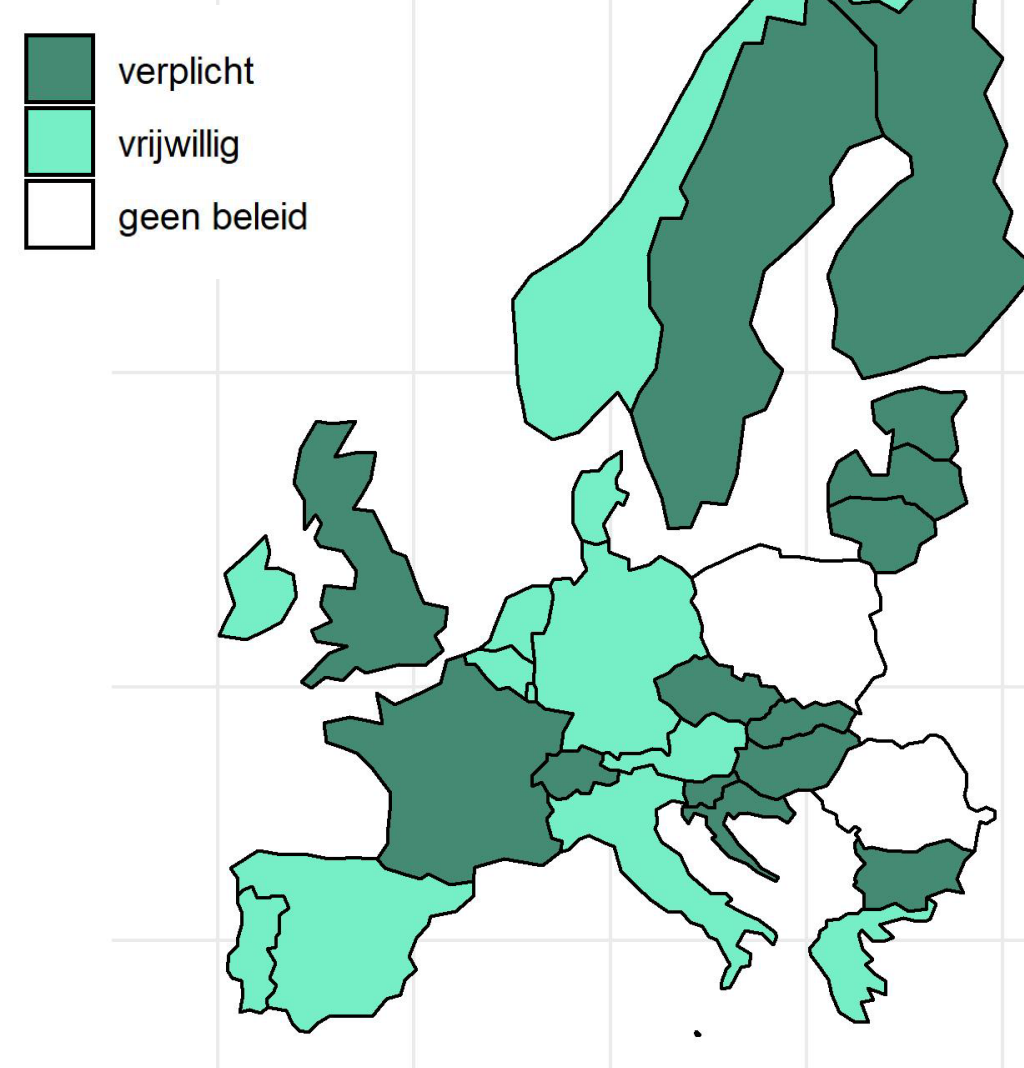

- Alle landen hebben richtlijnen voor voeding in het (primair en secundair) onderwijs

- De meeste landen (91\%) geven voedselrichtlijnen voor schoollunches op productniveau (figuur links) 


\section{Nationale richtlijnen voor de kwaliteit van schoollunches}

\section{Richtlijnen portiegrootte}
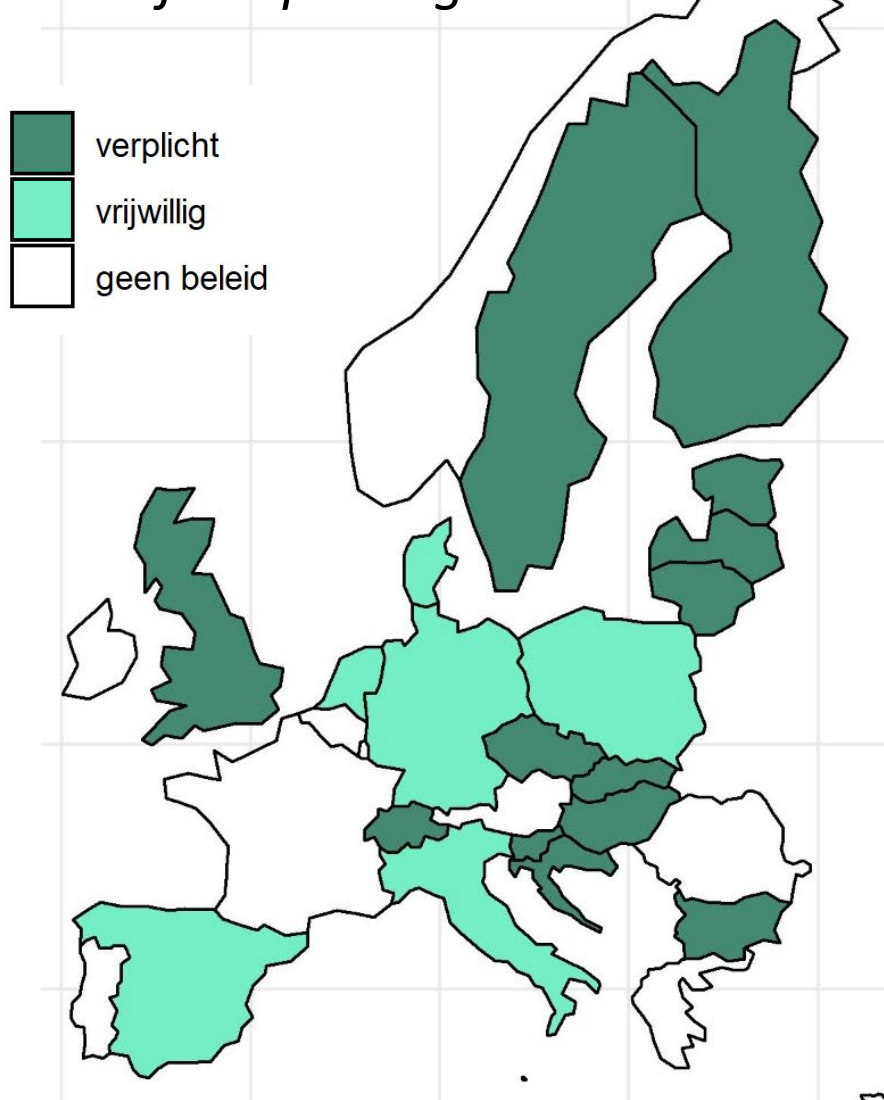

Richtlijnen voedingswaarde

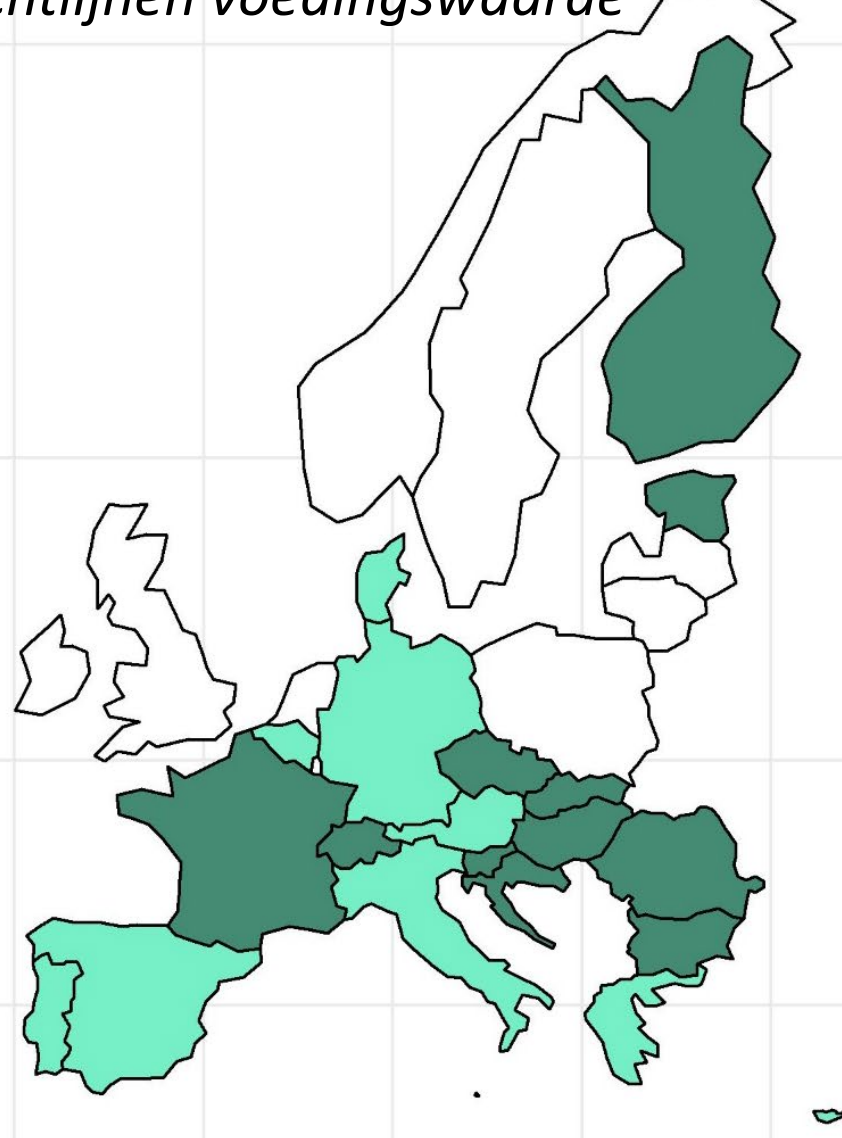

- $70 \%$ van de landen geeft richtlijnen over portiegrootte

- Bijv. met een voorbeeldbord (Finland)

- $67 \%$ van de landen geeft richtlijnen voedingswaarde

- Bijv. percentage van de dagelijkse (leeftijdsafhankelijke) energiebehoefte

- Andere voorbeelden van richtlijnen:

- Variatie in het menu

- Lokale en biologische producten 


\section{Hoe ziet de lunch eruit?}

Bijna alle landen bieden een warme maaltijd aan als lunch

- Vaak een self-service lunchbuffet

- In sommige landen worden (jongere) kinderen aan tafel bediend

(bijv. Frankrijk, Italië)

- In Frankrijk een 3-5 gangen menu

\section{Voorbeelden van lunches meegenomen vanuit huis als er geen schoollunch is}

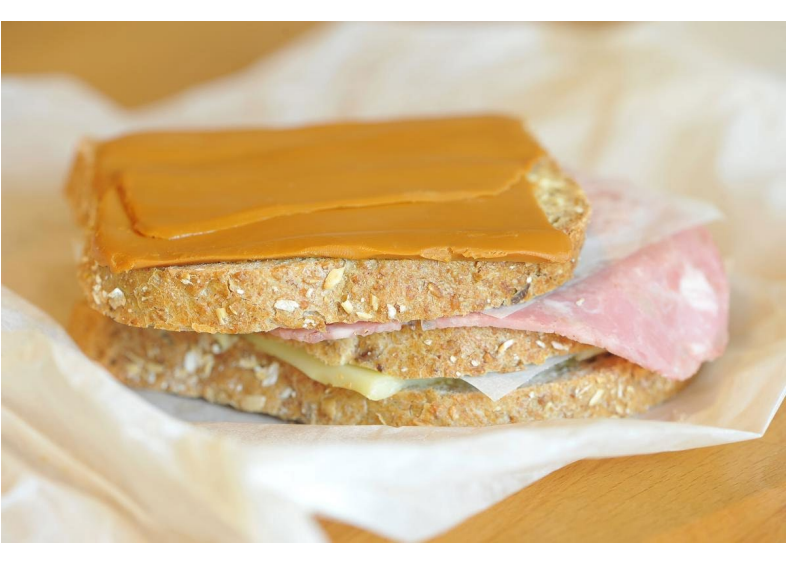

Noorwegen; geen schoollunch*
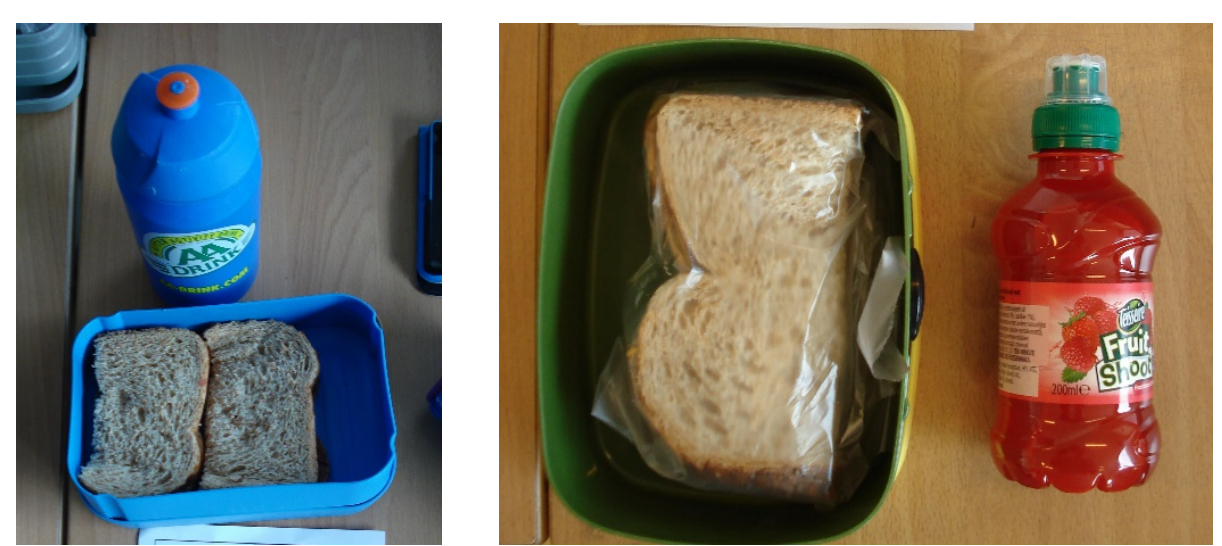

Nederland; geen schoollunch

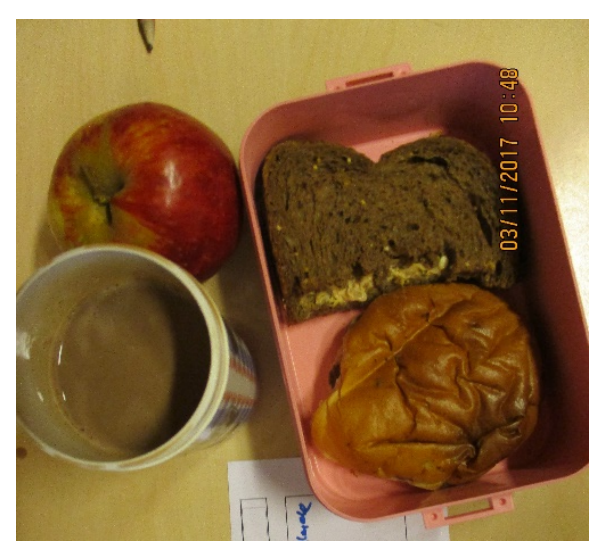

*Bron afbeelding: https://www.healthworks.my/takelook-school-lunches-around-world-31-countries/ 


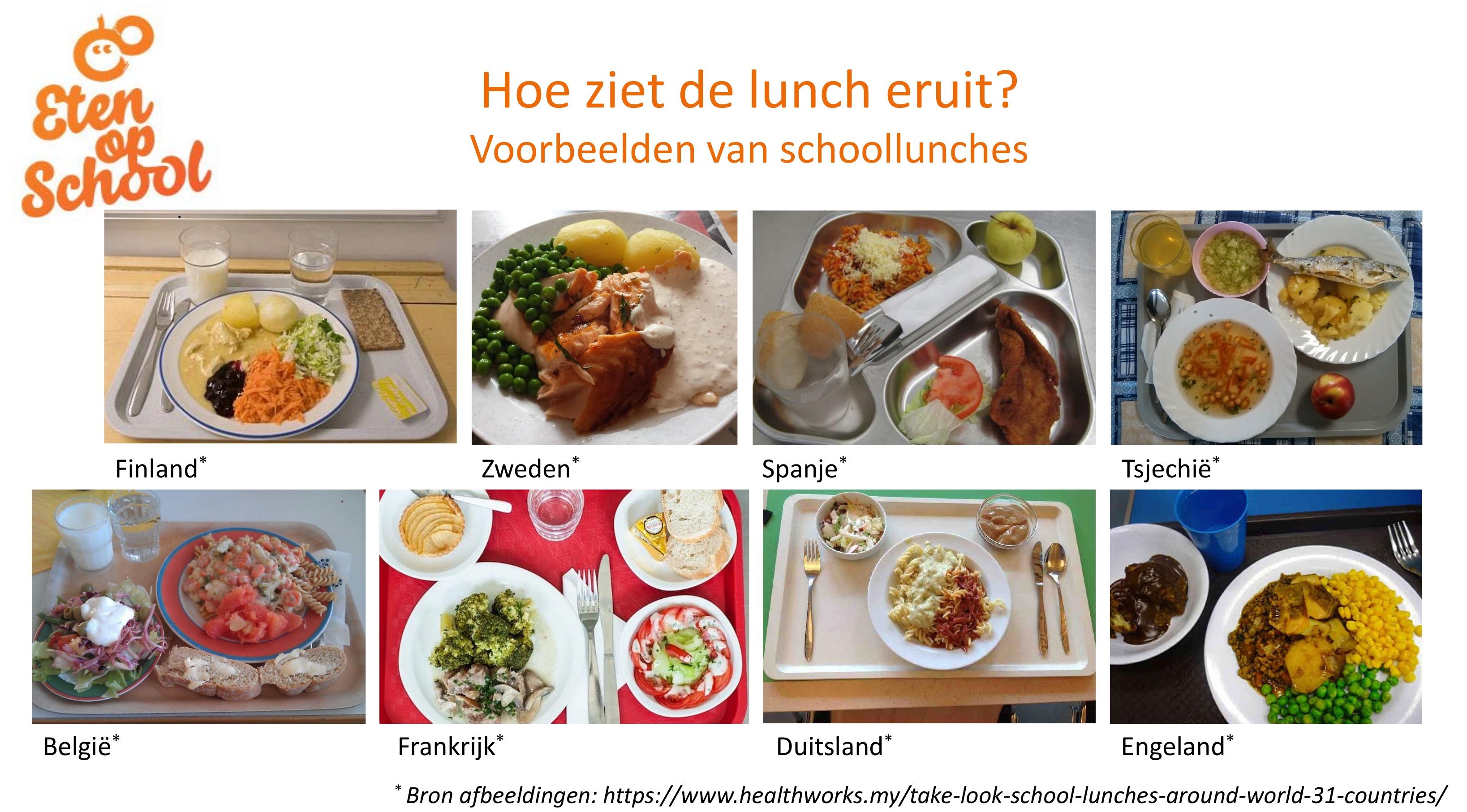




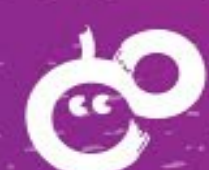 \\ cons \\ Sonod}

\section{FACILITEITEN VOOR SCHOOLLUNCHES}




\section{Keukenfaciliteiten voor de schoollunch}

- Mogelijkheden

- Keukens in de school

- Centrale keukens die meerdere scholen bedienen

- Externe cateraars

- Al deze mogelijkheden lijken in alle landen voor te komen

- De bereiding van schoolmaaltijden lijkt vaker te worden uitbesteed aan externe cateraars (vanwege de hoge kosten voor de keuken binnen de scholen) 


\section{Faciliteiten voor de eetruimte voor de schoollunch}

- Niet alle scholen hebben een aparte kantine of ruimte om te eten

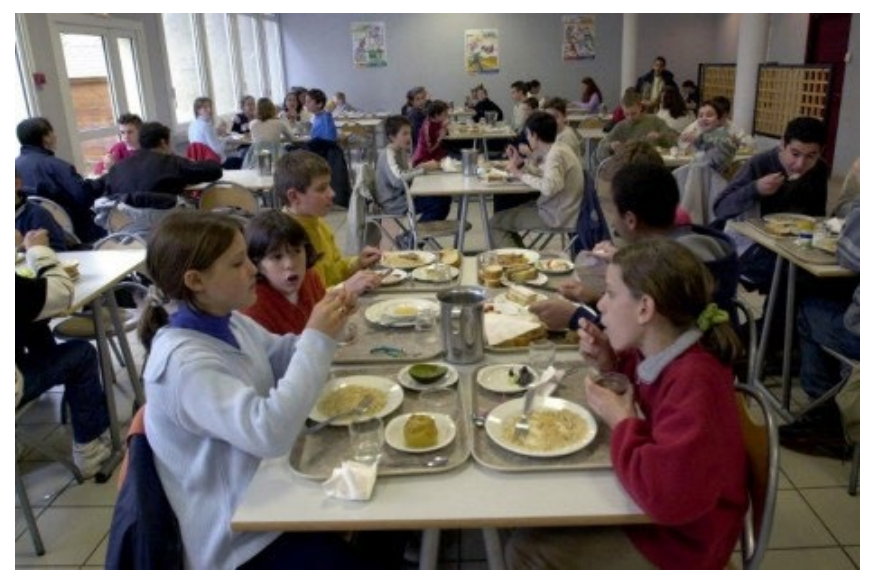

- Klaslokalen dienen dan als eetruimte

- In landen waar schoollunches gebruikelijk zijn, hebben de meeste scholen een kantine

- In sommige landen gelden wettelijke eisen voor de eetruimte

Kinderen lunchen in een school in Caen (Frankrijk) Foto $\underline{A F P}$ 


\section{Nationale richtlijnen schoollunchfaciliteiten}

\section{schiod}

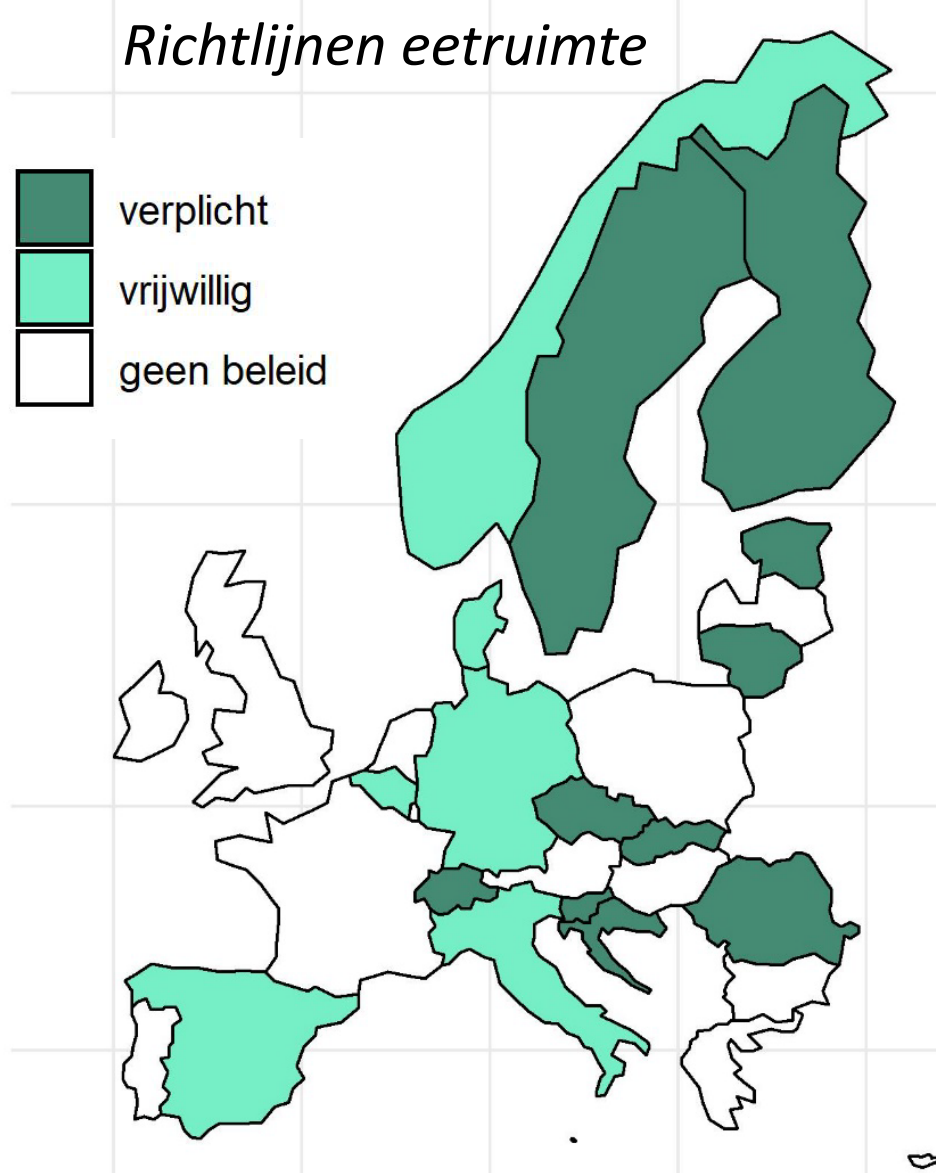

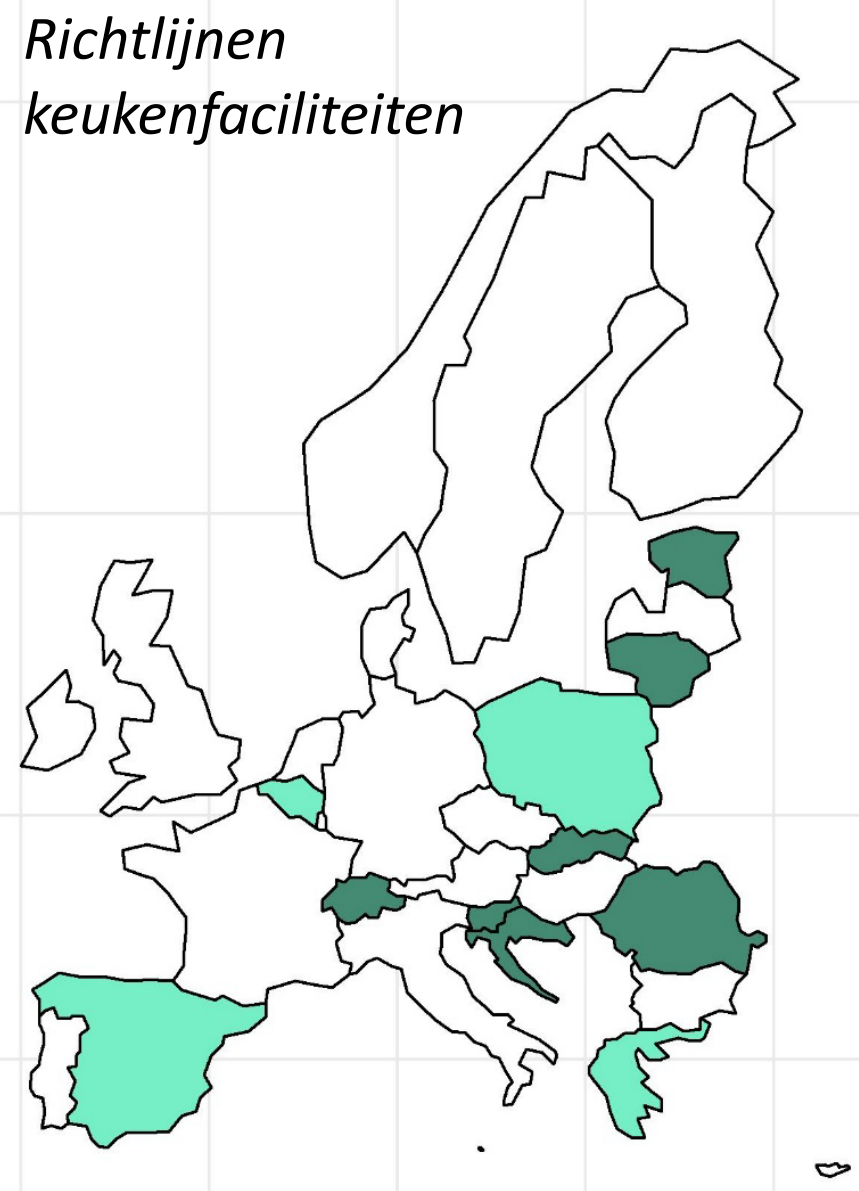

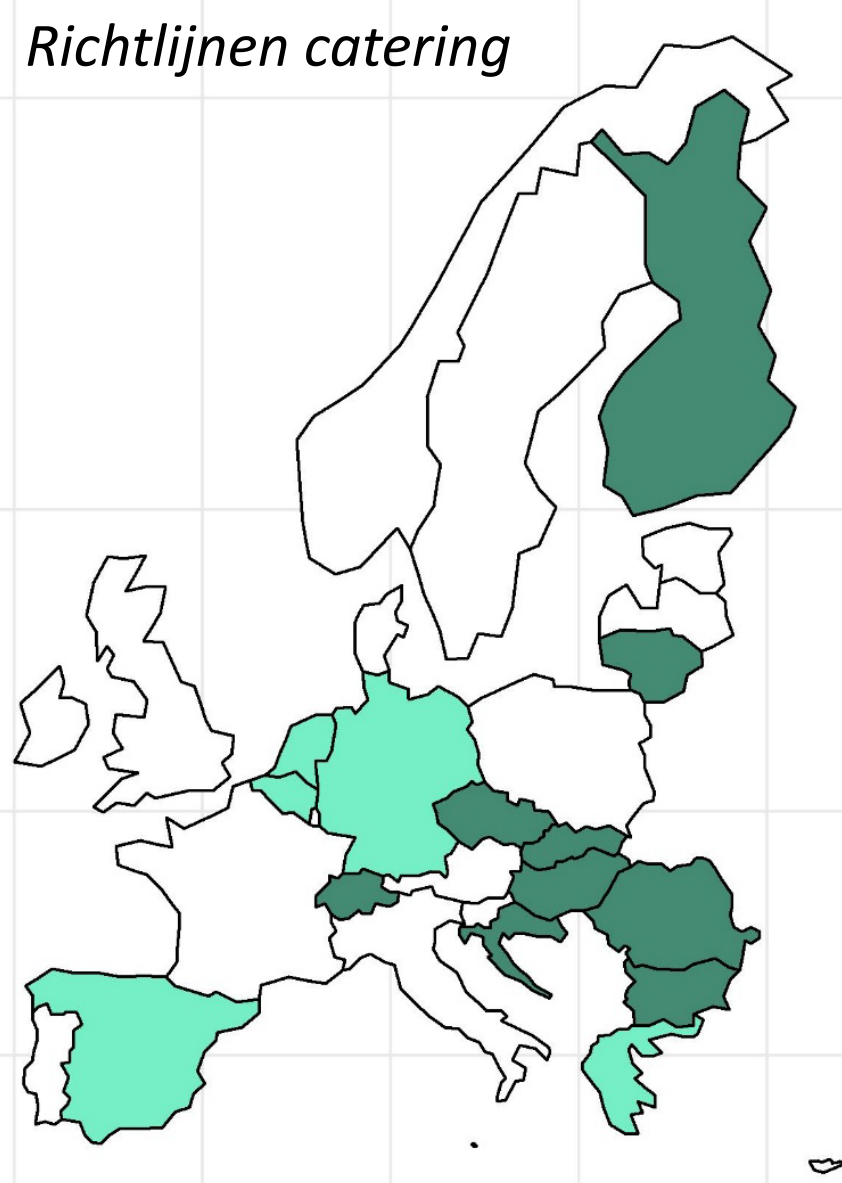

Bron: EU Science and policy report (2014) 


\section{oo
Stor
Scloot}

CONCLUSIES 


\section{Schoollunches in Europa: Wat leert deze verkenning ons?}

- De meeste Europese landen bieden een schoollunch aan, maar niet alle kinderen nemen deel aan de schoollunch

- Financiering van de schoollunch

- Minimaal gedeeltelijk gesubsidieerd in bijna alle landen

- Een gesubsidieerde schoollunch is geen garantie voor deelname, maar een gratis lunch verhoogt de deelname wel

- Houd rekening met het risico op stigmatisering wanneer een gratis of goedkopere lunch wordt aangeboden aan kinderen uit gezinnen met lagere inkomens 


\section{Schoollunches in Europa: Wat leert deze verkenning ons?}

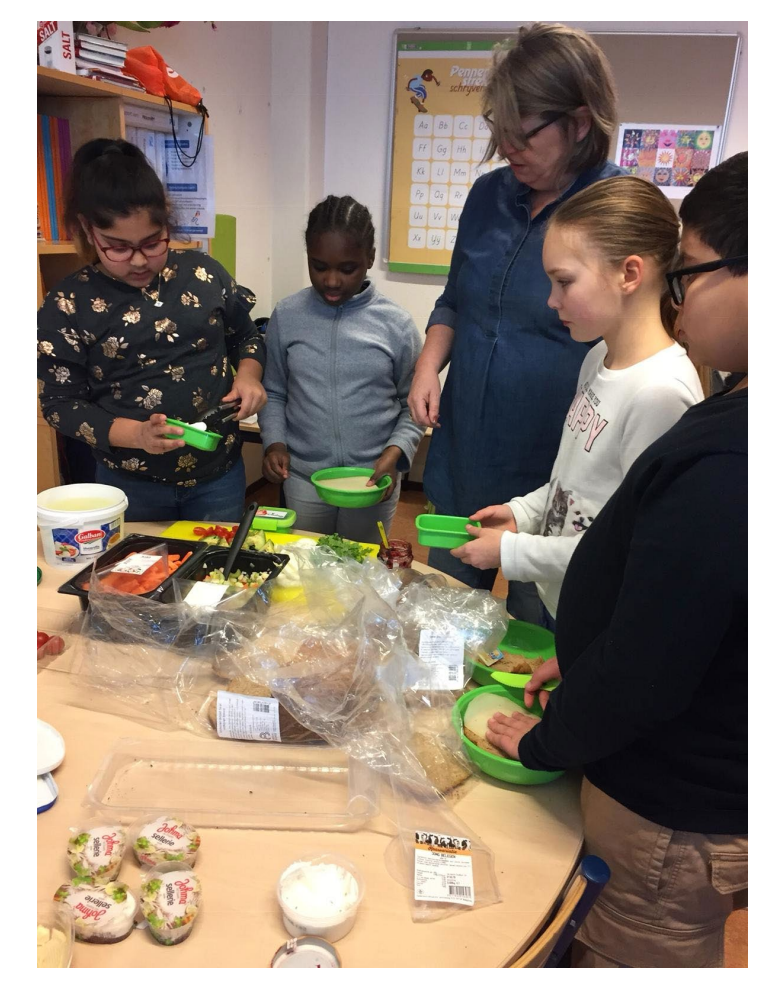

- Hoe ziet de lunch eruit?

- De meeste landen hebben richtlijnen (91\%) met algemene voedselrichtlijnen voor schoollunches

- De meeste landen bieden een warme maaltijd aan als schoollunch

- Schoollunch faciliteiten

- Kinderen lunchen in aparte kantines of eetruimtes, of klaslokalen dienen als eetruimte

- In landen waar schoollunches heel gebruikelijk zijn, hebben de meeste scholen een kantine 
Gezonde voeding draagt bij aan de gezondheid, het welbevinden en de ontwikkeling van kinderen

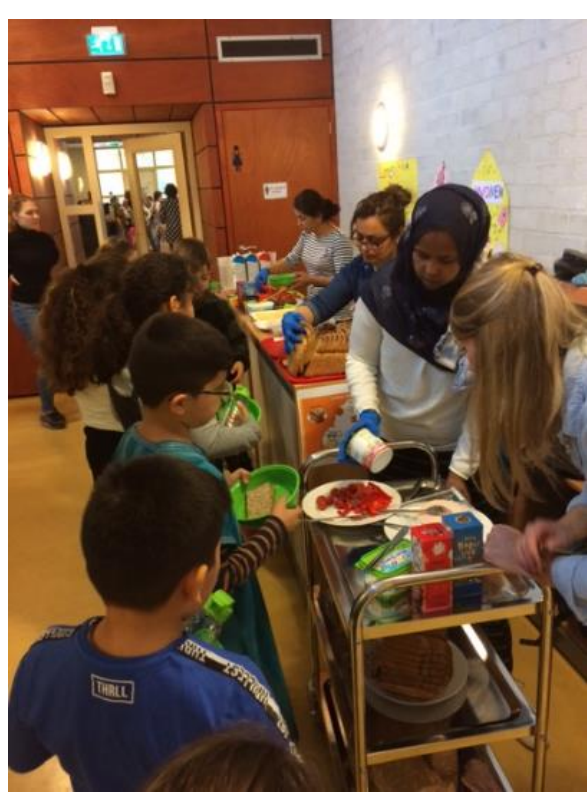

De meeste landen bieden een (deels) gesubsudieerde schoollunch aan, maar niet alle kinderen doen mee aan de schoollunch

De inzichten uit deze verkenning kunnen bijdragen aan de ontwikkeling en introductie van schoollunches in Nederland 


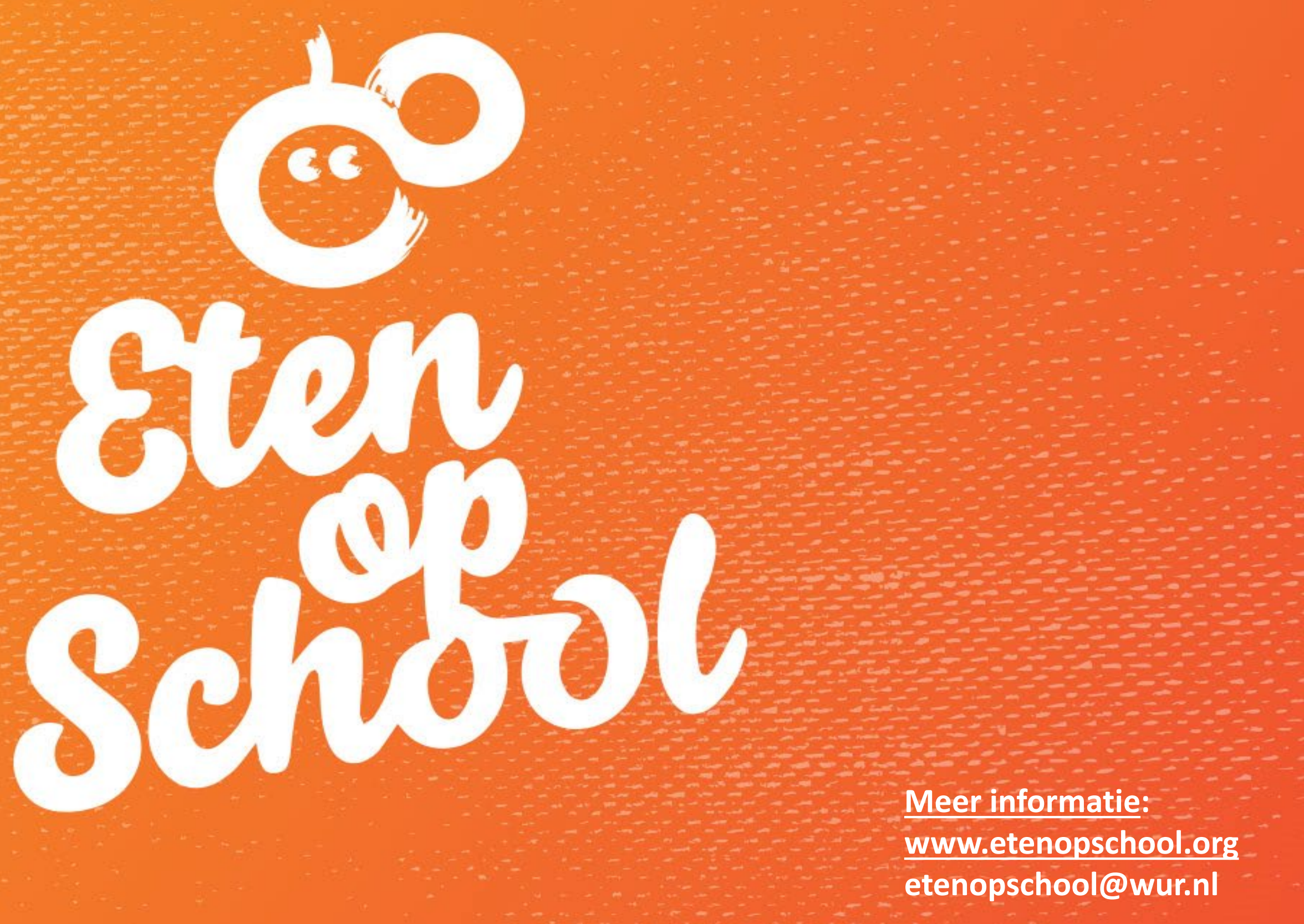

